\title{
The Transformation of Hospital Informatization Management Mode
}

\author{
Jinguo Wang ${ }^{1, a}$, Na Wang ${ }^{2, b, *}$ and Yang Gao ${ }^{2}$ \\ ${ }^{1}$ Department of Urology, the First Hospital of Jinlin University, China \\ ${ }^{2}$ Department of Anesthesiology, the First Hospital of Jinlin University, China \\ awangjinguolily@163.com, bwangna080613@163.com \\ *Corresponding author
}

Keywords: Informationization, Hospital, Management.

\begin{abstract}
Combining with the trend of social development and the literature, this paper illustrates the importance of informationization construction in hospital, especially its role in the modern hospital management and the social and economic benefits. The hospital information construction is the inevitable trend of modern hospital management.
\end{abstract}

\section{Introduction}

Modern hospitals is a versatile and open society organism, not only the level of the internal contact various departments, but also extension of oriented society which is extremely rich, involving with government, enterprises, communities, community, etc. Because of this, modern information and digitization technology in hospital has a more urgent and practical demand. By the construction of information, hospital is one of the important goals of management personnel at all levels [1].

Hospital information for patient services, to provide a real service and convenience for the patient, one is based on the patient as the center and in obedience to the established on the basis of reasonable process provides the quick service for the patient. The second is to improve the shortcomings of the original process, the realization of the hospital management reform. We work in the computer system specification process, centralized management, diversified service facilities arrangement, and realize the truly realize the "patient-centered", the scientific management [2].

\section{The main content and importance of information platform construction in hospital}

In medical data information, electronic medical records electronic medical records are not static, but dynamic intelligence sources of information. Electronic medical records reduce the burden of health care workers. To improve the efficiency of medical work of electronic medical records assist doctors medical record writing, through convenient editing tools, typical medical record templates, can greatly improve the efficiency of medical record writing, will the doctor liberated from heavy medical paperwork. Computer automatic processing orders, also can reduce the doctors and nurses unnecessary copying work, reduce the error probability [3]. Check your application result and paperless transfer, speed up the return of the results.

\subsection{Query system increases charging transparency}

It can be design teacher can through the condition the plot, the selection and design of a targeted teaching, not to the diagnosis of human use and study, independent design and preview surgery, to select the best treatment plan.

\subsection{Prevent mistakes}

Electronic medical records improve the quality of medical doctors on diagnosis and treatment decision process, the patient is essentially based on his knowledge of the according to the process of judgment. Although computer cannot replace the doctor's judgment, but can provide effective 
information fully, assist doctors make judgments [4]. The services include: medical record review of similar disease, help doctors to choose the best

\section{Improve the quality of health care and treatment}

The association of education communication and technology which is defined as education technology is the design of learning resources and learning process, development, application, management and evaluation of the theory and practice [5]. For applications in the field of medical education, it is to use modern teaching activities with modern information technology as the core of education technology, the teaching resources and teaching process in design, development, application, management and evaluation of the theory and practice. Including software and education resources, development and utilization should be put in the first place, which generally involve with more authoritative teaching materials [6].

\subsection{Patient as the center of service}

It can be directly to handle settlement in a hospital. Ginseng protect patients after medical costs more than just deliver medical personal responsibility proportion, special fund to pay part by the payment of hospital, and medical insurance settlement on a regular basis [7]. The move leaves out the patients to audit reimbursement of travel health care center, is well received by the patients with outpatient service a serious illness. Review and save the medicare agency staff reimbursement documents it takes a lot of time, improve the work efficiency and service quality health care institutions [8].

\subsection{The convenience for patients}

For the convenience of patients, local area network with Unionpay center with special line, from the hospital to Unionpay to pay fees, patients do not need to pay any fees, can brush Unionpay card settlement. In outpatient service charge management, hospital management program module embedded in the Unionpay machine interface, the patients in the outpatient fee or length of stay in the inpatient pay hospital accepting the gold and the settlement, can be directly brush card settlement. Not only provides the convenience for the patient but also reduce the risk of the patients to access large amounts of cash.

\subsection{The convenience for doctors}

Rates of construction of the hospital running cost savings, the establishment of large-scale hospital information construction and implementation, and scientific and rational use of the network storage all functions of all data and information, the traditional prescription, outpatient service log use network transmission to solve, the construction of the information for save the daily spending. Test specimen out belongs to very scientific platform, before the doctor prescribed a lot of paper according to the test item of mesh, after fees, inspection personnel according to the acquisition of each paper, specimens of a paper is a tube [9].

There are a lot of projects are carried out on the same instrument, so only need a tube of blood. Tradition not only time-consuming but also waste material, through the computer, in turn, interface, the instrument test specimens were calculated at the same time, and automatically merge inspection, only need a tube of blood, test machine for the project. Now you just need to pick a tube of blood specimen, namely reduce the workload of blood, and for the cost of the test tube is reduced.

\subsection{Feedback supervision}

Supervision by public opinion is to create an interactive cooperation, to accept the media public opinion information and to take the initiative to feedback opinion of the media supervision by public opinion. The author's hospital compound evening there is a "current politics news" program, answer people all aspects of problems by the government [10]. Dean came across people reflect the hospital "health check" red, immediately call the health department know the situation to find the audience through television. After the event, the audience is explained by telephone. The friend 
admits to understand health care provision. The above examples of surface, the role of the media supervision by public opinion is very big, can play a supervision and feedback information from different sides warning role [11].

\section{Summary}

Hospital information system is an important symbol of modern hospitals, also is the necessary infrastructure. Hospital information system should be suitable for the hospital management model of our situation. Hospital information system in the information is processing, standardization, standardization, scientific storage requirements. The implementation of hospital information system must be equipped with a set of perfect management system to ensure the smooth implementation. With the further deepening of the modern management technology, hospital information system has become a hospital management decision makers on one of the necessary means of modern hospital management.

\section{References}

[1] Mahdi Bahrami, Mazaher Ghorbani. Mohammad Arabzad. Information Technology (IT) as An Improvement Tool For Customer Relationship Management (CRM)[J]. Procedia - Social and Behavioral Sciences. 2012

[2] Hamid Tohidi, Mohammad Mehdi Jabbari. CRM as a Marketing Attitude Based on Customer's Information[J]. Procedia Technology. 2012

[3] Hamid Tohidi, Mohammad Mehdi Jabbari. The Necessity of Using CRM[J]. Procedia Technology. 2012

[4] Reiny Iriana, Francis Buttle. Strategic, Operational, and Analytical Customer Relationship Management[J]. Journal of Relationship Marketing. 2007 (4)

[5] Marion J. Ball. Hospital Information Systems:Perspectives Problems and prospects. International Journal of Medical Information. 2003

[6] Terry Huston. Seeurity Issues for Implementation of E-Medical Reeords. Communications of the ACM. 2001

[7] Gonsalves, GC., Lederer AL., Mahaney RC., Newkirk HE. "A Customer Resource Life Cycle Interpretation of the Impact of the World Wide Web on Competitiveness: Expeetions, and Achievements". Iniernational Journal of Electronic Commerce. 1999

[8] Richard L, Kitney CF. The Electronic Medical Record (MER) and object relational databases. Proceedings of the 20th Annual International Conference of the IEEE Engineering in Medicine and Biology Soeiety. 1998

[9] Ribiere V, Lasalle AJ, Khorrmashahgol R. Hospital information systems quality:a customer satisfaction assessment tool. System Sciences, 1999. HICSS-32. Proceedings of the 32nd Annual Hawaii International Conference. 1999

[10] Kanungo S. A framework for a medical information system. Engineering in Medicine and Biology Society. 1995

[11] Kitney RI, Bickram S, Claesen. Clinical trials of an electronic medical record system. Computers in Cardiology 1998. 1998 